\title{
GABA Regulates Dendritic Growth by Stabilizing Lamellipodia in Newly Generated Interneurons of the Olfactory Bulb
}

\author{
Eduardo Gascon, ${ }^{1}$ Alexandre G. Dayer, ${ }^{1,2}$ Marc-Olivier Sauvain, ${ }^{4}$ Gael Potter, ${ }^{1}$ Benoit Jenny, ${ }^{1}$ Mathias De Roo, ${ }^{1}$ \\ Eloisa Zgraggen, ${ }^{1}$ Nicolas Demaurex ${ }^{3}$ Dominique Muller, ${ }^{1}$ and Jozsef Z. Kiss ${ }^{1}$ \\ Departments of ${ }^{1}$ Neuroscience, ${ }^{2}$ Adult Psychiatry, and ${ }^{3}$ Cell Physiology and Metabolism, University of Geneva Medical School, CH-1211 Geneva, \\ Switzerland, and ${ }^{4}$ School of Life Sciences, Ecole Polytechnique Fédérale de Lausanne, CH-1015 Lausanne, Switzerland
}

\begin{abstract}
The initial formation and growth of dendrites is a critical step leading to the integration of newly generated neurons into postnatal functional networks. However, the cellular mechanisms and extracellular signals regulating this process remain mostly unknown. By directly observing newborn neurons derived from the subventricular zone in culture as well as in olfactory bulb slices, we show that ambient GABA acting through $\mathrm{GABA}_{\mathrm{A}}$ receptors is essential for the temporal stability of lamellipodial protrusions in dendritic growth cones but did not interfere with filopodia dynamics. Furthermore, we provide direct evidence that ambient GABA is required for the proper initiation and elongation of dendrites by promoting the rapid stabilization of new dendritic segments after their extension. The effects of GABA on the initial formation of dendrites depend on depolarization and $\mathrm{Ca}^{2+}$ influx and are associated with a higher stability of microtubules. Together, our results indicate that ambient GABA is a key regulator of dendritic initiation in postnatally generated olfactory interneurons and offer a mechanism by which this neurotransmitter drives early dendritic growth.
\end{abstract}

Key words: dendritic development; GABA; neurogenesis; lamellipodia; subventricular zone; microtubule

\section{Introduction}

In the mammalian brain, ongoing neurogenesis maintains neuronal replacement in the olfactory bulb $(\mathrm{OB})$ throughout life (Lois et al., 1996; Belluzzi et al., 2003; Carleton et al., 2003). Newly generated neurons from the subventricular zone (SVZ) migrate through the rostral migratory stream to the olfactory bulb, where they rapidly initiate dendritic growth and establish dendrodendritic contacts with mitral cells and other granule cells (AlvarezBuylla and Garcia-Verdugo, 2002; Bolteus and Bordey, 2004; Lledo and Saghatelyan, 2005). Although much has been learned about the sequential steps of neuroblast maturation in the olfactory bulb (Carleton et al., 2003), the mechanism and regulatory factors that control the initial period of dendrite formation and thus the first distinguishable event of integration of newly generated neurons, remain poorly understood. Identification of these mechanisms might be crucial for the development of strategies aimed at promoting the insertion of immature cells into damaged brain circuits.

Recent work pointed to importance of GABA in the control of neuronal development (Ben-Ari, 2002; Ge et al., 2006). Although

\footnotetext{
Received June 14, 2006; revised Nov. 2, 2006; accepted Nov. 2, 2006.

This work was supported by Swiss National Foundation Grant 31-64030.00 and by European Community Grant Promemoria 512012-2005 (J.Z.K.). We thank S. Chliate and C. Saadi for technical assistance. We are grateful to Jean-Marc Fritschy for the antibodies against $\mathrm{GABA}_{A}$ receptor subunits.

Correspondence should be addressed to JozsefZ. Kiss, Department of Neuroscience, University of Geneva Medical School, 1, Rue Michel Servet, CH-1211 Geneva, Switzerland. E-mail: jozsef.kiss@medecine.unige.ch.

D01:10.1523/JNEUROSCI.4508-06.2006

Copyright $\odot 2006$ Society for Neuroscience $\quad$ 0270-6474/06/2612956-11\$15.00/0
}

GABA is the principal inhibitory neurotransmitter in the adult brain, it might in fact be excitatory in immature neurons including newborn neurons in the adult olfactory bulb (Ben-Ari, 2002; Carleton et al., 2003). Although it has been demonstrated that depolarizing GABA signaling modulates dendritic development of postnatally generated neurons (Ge et al., 2006), the mechanisms of these effects remain mostly unknown. Furthermore, the potential role of GABA signaling in the initial phase of dendrite generation has not been tested.

Here, we explored the mechanisms by which ambient GABA might regulate dendritic initiation and early dendritic growth of postnatally generated SVZ neurons. Using time-lapse microscopy, we observed that $\mathrm{GABA}_{\mathrm{A}}$ controls dendritic growth cone dynamics and promotes the stability of lamellipodia. We found, in addition, that $\mathrm{GABA}_{\mathrm{A}}$ activity is crucial for the correct stabilization of newly formed and preexisting dendrites. Finally, we show that, even in the olfactory bulb, lamellipodia stability and dendritic growth of newly generated olfactory interneurons is affected during $\mathrm{GABA}_{\mathrm{A}}$ stimulation/inhibition. Thus, ambient GABA and $G_{A B A}$ receptor activation seem to be essential for the appropriate initiation and stability of newly generated primary dendrites.

\section{Materials and Methods}

Animals and viral injection. Sprague Dawley rats were bred in an animal facility of the University of Geneva Medical School. They were kept on a $12 \mathrm{~h}$ light/dark cycle at constant temperature $\left(22^{\circ} \mathrm{C}\right)$ with food and water ad libitum. All experimental procedures were in accordance with the Society for Neuroscience and European Union guidelines and were ap- 
proved by the Geneva authorities (Committee for Animal Experimentation).

Labeling of the SVZ cells was done by means of a lentiviral vector carrying green fluorescent protein (GFP) under the regulation of the ubiquitin promoter. Attenuated lentiviral particles were produced by transfection of 293T cells according to standard protocols (Klages et al., 2000). Pups at postnatal day 0 (P0) were anesthetized with a mixture of isoflurane (Foren; $100 \%), \mathrm{O}_{2}(30 \%)$, and air $(70 \%)$ and maintained in a stereotaxic frame. A midline skin incision was performed at the surface of the skull, and a small burr-hole was drilled through the skull over the right hemisphere (coordinate from the bregma: $0 \mathrm{~mm}$ anterior, $1 \mathrm{~mm}$ lateral). One microliter of a suspension containing the lentiviral vector at a concentration of $5 \times 10^{9}$ transducing units/ml was stereotactically injected with a Hamilton syringe at a depth of $1.8 \mathrm{~mm}$ from the surface of the brain.

Cultures and reagents. Dissociated neuronal cultures from the SVZ were prepared from newborn rats (P0) as described previously (Gascon et al., 2005). Briefly, the SVZ was dissected from coronal slices, dissociated mechanically, trypsinized, and purified using Percoll gradient centrifugation. Cells were plated onto polyornithine (Sigma, St. Louis, MO)coated cell culture supports at a plating density of 5000 cells $/ \mathrm{cm}^{2}$ and allowed to grow in Neurobasal medium (Invitrogen, Paisley, UK) with 2\% B27 supplement (Invitrogen), 2 mu L-glutamine (Invitrogen), and 1 mm sodium pyruvate (Sigma). For immunocytochemistry, cells were cultured onto coverslips in $35 \mathrm{~mm}$ Petri dishes (Falcon, Plymouth, UK); for RNA extraction and microtubule stability, onto $100 \mathrm{~mm}$ Petri dishes (Falcon); and for time-lapse microscopy, onto coverslips that were fixed to the bottom of perforated $50 \mathrm{~mm}$ Petri dishes (Falcon).

For slice cultures, injected rats were decapitated at P8-P14, and the brain was removed and rapidly transferred into ice-cold $\mathrm{Ca}^{2+}$ - and $\mathrm{Mg}^{2+}$-free HBSS. Then, the hemispheres were separated and cut sagittally using a vibratome. Two hundred micrometer slices containing the olfactory bulb were cultured onto $0.4 \mathrm{~mm}$ culture plate inserts (Millicell; Millipore, Carrigtwohill, Ireland). The medium was the same as for dissociated cultures but supplemented with $100 \mathrm{U} / \mathrm{ml}$ penicillin and 0.15 $\mathrm{mg} / \mathrm{ml}$ streptomycin.

GABA, bicuculline methobromide, 6-imino-3-(4-methoxyphenyl)1(6H)-pyridazinebutanoic acid (SR95531), 1,2,5,6-tetrahydropyridin-4yl)methylphosphinic acid (TPMPA), and $\left[S-\left(R^{*}, R^{*}\right)\right]$-[3-[[1-(3,4-dichlorophenyl)ethyl]amino]-2hydroxypropyl] (cyclohexylmethyl) phosphinic acid (CGP54626), and ryanodine were purchased from Tocris Bioscience (Bristol, UK); 5-bromo-2'-deoxyuridine (BrdU), nocodazole, nifedipine, and mibefradil from Sigma; and BAPTA-AM from Invitrogen.

Patch-clamp recording. All experiments were performed at room temperature $\left(20^{\circ} \mathrm{C}\right)$. Patch-clamp recordings were performed with an Axopatch 200B amplifier (Molecular Devices, Sunnyvale, CA). Patch electrodes (3-6 M $\Omega$ ) were made from borosilicate glass using a DMZuniversal horizontal electrode puller (Zeitz Instruments, Augsburg, Germany). The external solution contained the following (in mM): $150 \mathrm{NaCl}$, $5 \mathrm{KCl}, 1 \mathrm{CaCl}_{2}, 10$ HEPES, 10 glucose, pH 7.3 (with $\mathrm{NaOH}$ ). The culture dish (total bath volume, $1 \mathrm{ml}$ ) was continuously superfused with extracellular solution at a rate of $2 \mathrm{ml} / \mathrm{min}$. The pipette solution contained the following (in mM): $142 \mathrm{KCl}, 10 \mathrm{NaCl}, 2 \mathrm{MgCl}_{2}, 10$ HEPES, $10 \mathrm{EGTA}, \mathrm{pH}$ 7.3. Perforated patch-clamp experiments were made by adding gramicidin (Sigma) in the pipette medium. The gramicidin stock solution $(250$ $\mu \mathrm{g} / \mathrm{ml}$ ) was prepared in DMSO and diluted to the pipette solution (1/ 1000) just before the recording session. GABA was applied locally by a pressure pipette placed near the recorded cells, and antagonists were bath applied. Data were acquired and analyzed using a Digidata 1200 and pClamp 8 (Molecular Devices) or Igor Pro (WaveMetrics, Portland, OR). $I-V$ relationship plotting and linear regression were performed with the freeware Qtiplot.

Immunofluorescence. Immunostaining of cultures and slices was performed as described previously (Zhang et al., 2003). Briefly, cultures were fixed with cold paraformaldehyde (4\%) in phosphate buffer, $\mathrm{pH} 7.4$, rinsed, blocked for $1 \mathrm{~h}$ in PBS- $0.5 \%$ BSA- $0.3 \%$ Triton X-100, and incubated overnight at $4^{\circ} \mathrm{C}$ with the primary antibody diluted in blocking solution. They were then incubated at room temperature with the appropriate secondary antibody Alexa 488 or 555 (Invitrogen) diluted in PBS for $60 \mathrm{~min}$. For BrdU detection, slices were incubated with $2 \mathrm{M} \mathrm{HCl}$ and rinsed in PBS before the reaction with the primary antibody. Primary antibodies used were mouse monoclonal anti- $\beta$-tubulin isotype III (Sigma) (1:1000 dilution), monoclonal rat anti-BrdU (Accurate Chemical, Westbury, NY) (1:500 dilution), rabbit polyclonal anti-GFP (Invitrogen) (1:2000 dilution), rabbit polyclonal anti-KCC2 (Upstate Biotechnology, Lake Placid, NY) (1:300 dilution), and rabbit polyclonal $\alpha 4$ receptor (1:200 dilution) (Santa Cruz Biotechnology, Santa Cruz, CA). Primary antibodies for $\mathrm{GABA}_{\mathrm{A}}$ subunits $\alpha 1$ (rabbit polyclonal; dilution, $1: 2000$ ), $\alpha 2$ (raised in guinea pig; dilution, 1:5000), $\alpha 3$ (raised in guinea pig; dilution, 1:2000), and $\alpha 5$ (raised in guinea pig; dilution, 1:3000) were generously provided by Prof. J. M. Fritschy (Institute of Pharmacology, University of Zurich, Zurich, Switzerland).

Time-lapse microscopy. Dissociated living cultures were observed on an inverted microscope (Nikon Eclipse TE2000-U; Nikon, Zurich, Switzerland) equipped with a chamber where temperature and $\mathrm{CO}_{2}$ were kept at $37^{\circ} \mathrm{C}$ and $5 \%$, respectively. Time-lapse images at different intervals $(5,60$, or $600 \mathrm{~s}$ ) were acquired with a $60 \times$ Nikon objective and a digital camera (Retiga EX; Qimaging, Burnaby, British Columbia, Canada) controlled by Openlab software (Improvision, Tübingen, Germany).

Slices cultures were mounted in a custom-made chamber specially adapted for the observation of cultures directly on the insert plates. Confocal $z$-stacks series of fluorescent GFP cells were acquired with a $40 \times$ Zeiss (Oberkochen, Germany) objective (numerical aperture, 1.3) using a Nipkow spinning disc confocal microscope. The incident laser (Coherent, Dieburg, Germany) beam (488 nm) was coupled with a Yokogawa (Tokyo, Japan) spinning disc confocal scan head (QLC100; Visitech International, Sunderland, UK) mounted on an inverted microscope (Axiovert 200M; Zeiss). Fluorescence images (520 nm long-pass filter) were captured with a cooled 12-bit TE/CCD interlined Coolsnap HQ Photometrics camera (Ropper Scientific, Tucson, AZ). Time-lapse $z$-stacks were acquired with Metafluor software (Universal Imaging Corporation, West Chester, PA).

Determination of microtubule stability. The protocol to determine microtubule stability was described previously (Vaillant et al., 2002). Briefly, dissociated cultures of SVZ-derived neurons were treated with GABA, bicuculline, or vehicle for $6 \mathrm{~h}$, and then washed with $80 \mathrm{~mm}$ PIPES (Sigma), pH 6.8, $5 \mathrm{~mm} \mathrm{EGTA} \mathrm{(Sigma),} \mathrm{and} 1 \mathrm{~mm} \mathrm{MgCl}_{2}$ (Sigma) at $37^{\circ} \mathrm{C}$. Cells were incubated for $5 \mathrm{~min}$ at $37^{\circ} \mathrm{C}$ in $1 \mathrm{ml}$ of soluble tubulin extraction buffer (Joshi and Cleveland, 1989) with the addition of Complete Mini Protease Inhibitors (Roche, Mannheim, Germany). The extraction buffer was then pipetted from the dishes and spun for 2 min at 10,000 $\mathrm{rpm}$ at room temperature, and the supernatant was removed and stored at $-80^{\circ} \mathrm{C}$. Then, $1 \mathrm{ml}$ of microtubule depolymerizing buffer (Thrower et al., 1991) containing the Complete Mini Protease Inhibitors (Roche) was added to the dish, and cells were scraped into the tube containing the pellet from the soluble fraction. The cells were sonicated for $10 \mathrm{~s}$ two times, incubated $1 \mathrm{~h}$ on ice, and spun for $10 \mathrm{~min}$ at $10,000 \mathrm{rpm}$ and at $4^{\circ} \mathrm{C}$. The supernatant was removed and stored at $-80^{\circ} \mathrm{C}$. Twenty-five micrograms of each fraction were electrophoresed into a $10 \%$ SDSpolyacrylamide gel. After electrophoresis, the proteins were transferred to polyvinylidene difluoride membrane in $25 \mathrm{~mm}$ Tris, $192 \mathrm{~mm}$ glycine, and $20 \%$ methanol, and blocked in blocking buffer (5\% nonfat dry milk in PBS and $0.1 \%$ Tween 20 ) for $1 \mathrm{~h}$ at room temperature. The blots were incubated in primary mouse monoclonal antibody anti- $\alpha$-tubulin (1: 8000; Sigma) overnight at $4^{\circ} \mathrm{C}$. After three washes in PBS, the membrane was incubated in donkey anti-mouse horseradish peroxidase-linked secondary antibody (1:5000; Bio-Rad, Hercules, CA) for $2 \mathrm{~h}$ at room temperature and developed using the enhanced chemoluminescence reagents according to the manufacturer's instructions (ECL; Amersham Biosciences, Little Chalfont, UK). Absolute tubulin levels were quantified using bovine purified tubulin (Cytoskeleton, Denver, CO) as a standard. These values were normalized to total protein levels in the soluble and polymerized fractions to yield the percentage of soluble and polymerized tubulin present within the cell.

SYBR Green assay. Total RNA was extracted using an RNA-easy micro kit (Qiagen, Hilden, Germany) following the manufacturer's instructions except that DNase I treatment was done on the isolated total RNA and not on the column. A total of $50 \mathrm{ng}$ of total RNA was converted to 
cDNA using Sensiscript reverse transcriptase (Qiagen). Reverse transcription was performed in a T3 thermocycler (Biometra, Göttingen, Germany) for $1 \mathrm{~h}$ at $37^{\circ} \mathrm{C}$.

Real-time PCR was performed in an ABI Prism 7900 Sequence Detection system (Applied Biosystems, Foster City, CA). PCRs were performed in triplicate using SYBR Green PCR Master Mix (Applied Biosystems). Each SYBR Green reaction ( $10 \mu \mathrm{l}$ total volume) contained $1 \mu \mathrm{l}$ of cDNA as template and $0.3 \mu \mathrm{M}$ of each primer. Controls without template DNA (water and reverse transcription reaction) were always negative. The reactions were incubated at $95^{\circ} \mathrm{C}$ for $10 \mathrm{~min}$ to activate the HotStar Taq polymerase followed by 40 cycles at $95^{\circ} \mathrm{C}$ for $15 \mathrm{~s}$ (denaturation) and at $60^{\circ} \mathrm{C}$ for $1 \mathrm{~min}$ (annealing and extension). $\beta$-Actin was used as internal control. The oligonucleotide primers used for PCR were as follows: for KCC2, 5'-CAGATGCACCTCACCAAGAA- ${ }^{\prime}$ and $5^{\prime}$-TCTCTTCGGGAACATTGAGG-3'; for actin, 5'-CGTGGGCCGCCCTAGGCACCAG-3' and 5' -TTGGCCTTAGGGTTCAGGGGGG-3'.

Because SYBR Green indiscriminately binds to double-stranded DNA, other products in the PCR such as primer dimers may be detected along with the target gene. To verify that the SYBR Green dye detected only one PCR product, the samples were subjected to the heat dissociation protocol after the final cycle of the PCR.

Calcium imaging. Experiments were performed in HEPES-buffered solution containing the following (in $\mathrm{mM}$ ): $140 \mathrm{NaCl}, 5 \mathrm{KCl}, 1 \mathrm{MgCl}_{2}, 2$ $\mathrm{CaCl}_{2}, 20$ HEPES, $10 \mathrm{~mm}$ glucose, $\mathrm{pH}$ 7.4. Glass coverslips were mounted in a thermostatic chamber (Harvard Apparatus, Holliston, MA) equipped with gravity feed inlets and vacuum outlet for solution changes. Cells were imaged on an Axiovert s100 using a $100 \times$ (numerical aperture, 1.3) oil-immersion objective (Zeiss). Cells were loaded for $30 \mathrm{~min}$ with $250 \mathrm{~nm}$ fura-2 AM at room temperature in the dark, washed twice, and equilibrated for 15-20 min to allow de-esterification. To monitor $\left[\mathrm{Ca}^{2+}\right]_{\mathrm{i}}$, cells were alternatively excited at 340 and $380 \mathrm{~nm}$ with a monochromator (DeltaRam; Photon Technology International, Birmingham, NJ) through a 430 DCLP dichroic mirror, and emission was monitored through a 510WB40 filter (Omega Optical, Brattleboro, VT). Fluorescence emission was imaged using a cooled, 16-bit CCD back-illuminated frame transfer MicroMax camera (Princeton Instruments, Trenton, NJ). Image acquisition and ratiometric analysis were performed with the Metafluor software (Universal Imaging Corporation).

Image acquisition and data analysis. Immunofluorescence of dissociated cultures was observed by means of a fluorescent microscope (Nikon Eclipse TE2000-U) and photographed with a digital camera (Retiga EX; Qimaging). For quantitative analysis of dendritic arbors, cells were stained with anti- $\beta$-tubulin isotype III antibody and photographed. The following parameters that describe most aspects of dendritic architecture were then determined: number of primary dendrites, length of dendrites, and number of dendritic branches. Total dendritic length was measured by drawing all visible processes with Image J. The remaining parameters were manually scored on the image.

In slice cultures, double-labeled BrdU/GFP cells were selected for analysis. Each neuron was first imaged using a $40 \times$ objective (numerical aperture, 1.3) and $z$-sectioned at $1 \mu \mathrm{m}$ increments using LSM 510 confocal microscope (Zeiss). Single image stacks were then collapsed, imported in Photoshop (Adobe Systems, San Jose, CA), and mounted to obtain a two-dimensional reconstruction of the entire neuron subsequently used for quantitative analysis of dendritic length and complexity with Image J.

In time-lapse experiments, different parameters were analyzed in the image or $z$-stack series using Image J. The parameters used in these experiments were calculated as follows: (1) lamellipodia frequency: percentage of images in a time lapse in which lamellipodia were visible; (2) lamellipodia/cell: total number of lamellipodia per cell visible during a time-lapse sequence; (3) lamellipodia lifetime: interval when a given lamellipodia was observed (expressed in seconds); (4) lamellipodia formation rate: number of lamellipodia formed in a defined interval (expressed in events/minute); (5) frequency of elongation/retraction: percentage of images in a time lapse in which elongation/retraction was observed (elongation/retraction was defined as an increase/decrease in dendritic length at a time point compared with the previous one); and (6) elonga- tion/retraction speed: elongation/retraction during the observation period (expressed in micrometers/hour).

Statistical analysis. Values were expressed as means \pm SD and analyzed for statistical significance using two-tailed paired $t$ test (time-lapse experiments), Fisher's test (electrophysiological experiments), or one-way ANOVA followed by the all-pairwise comparison Holm-Sidak test (all other experiments).

\section{Results}

\section{$\mathrm{GABA}_{\mathrm{A}}$ activity stimulates dendritic arbor development in} early stages of differentiation

We first examined the effects of GABA signaling on dendritic development in vitro using purified neurons from the SVZ of newborn rats (Gascon et al., 2005). These cells exhibit many features of newly generated neurons in vivo such as strong PSANCAM (polysialylated neural cell adhesion molecule) immunoreactivity, the ability to synthesize GABA, the presence of dendritic processes, and the lack of axons (Gascon et al., 2005). Neurons initially exhibit a round shape for the first few hours after plating, and then extend perisomal lamellipodia that may progressively transform into an actin-rich growth cone (Fig. $1 A$ ). The nascent growth cone, connected to the soma with a thin shaft, gradually migrates away from the cell body to form a dendritic process (Fig. 1 $A$ ).

In agreement with previous reports (Stewart et al., 2002), we observed that SVZ-derived neurons already expressed different $\alpha$-subunit immunoreactivity $(\alpha 2,3,4,5)$ of the $\mathrm{GABA}_{\mathrm{A}}$ receptors after $1 \mathrm{~d}$ in vitro (DIV) (supplemental Fig. 1, available at www. jneurosci.org as supplemental material). To investigate the role of ambient GABA in dendritic development, cells were plated in the presence of bicuculline (a specific antagonist of $\mathrm{GABA}_{\mathrm{A}}$ receptors) and their trees analyzed post hoc $60 \mathrm{~h}$ later. Compared with control cultures, cells treated with bicuculline $(20 \mu \mathrm{M})$ showed a net reduction in dendritic complexity (Fig. 1A,B). As illustrated in Figure $1 B$, these changes affected primarily the number and length of primary dendrites. In contrast, the number of branches per dendritic field was not modified (Fig. 1C). Treatment with $\mathrm{GABA}_{\mathrm{B}}(\mathrm{CGP} 54626 ; 10 \mu \mathrm{M})$ or GABA $_{\mathrm{C}}$ (TPMPA; 15 $\mu \mathrm{M}$ ) antagonists resulted in no changes in dendritic arbors (data not shown) arguing against a nonspecific toxic effect of bicuculline. Furthermore, stimulation of GABA receptors with a single pulse of exogenous GABA $(100 \mu \mathrm{M})$ led to the opposite effects of bicuculline (Fig. $1 B, C$ ). Interestingly, when more mature neurons were challenged with the same dose of bicuculline (treatment started at 5 DIV), we did not observe any modification of dendritic trees (data not shown). Together, these results demonstrate that ambient GABA and $\mathrm{GABA}_{\mathrm{A}}$ activity markedly affected the formation of dendritic arbors of newly generated neurons by acting specifically during the first stages of development.

\section{GABA activity modulates dendritic development of newly generated neurons in the olfactory bulb}

To verify whether ambient GABA also affected early dendritic development in a tissue context, we analyzed labeled, newly generated neurons in OB slices. To identify the population of newly generated cells at early stages of maturation, we used a protocol that combined BrdU birth dating together with the injection of GFP lentivirus in the lateral ventricle. Briefly, viral infection was followed by a single intraperitoneal injection of BrdU $(50 \mathrm{mg} / \mathrm{kg})$ $4 \mathrm{~d}$ later. Eight days after BrdU administration, sagittal slices of the $\mathrm{OB}$ were prepared, and BrdU+/GFP + cells present in the $\mathrm{OB}$ were analyzed (Fig. 2A,B). This protocol allowed us to precisely analyze, through GFP staining, the morphology of stably labeled 
A
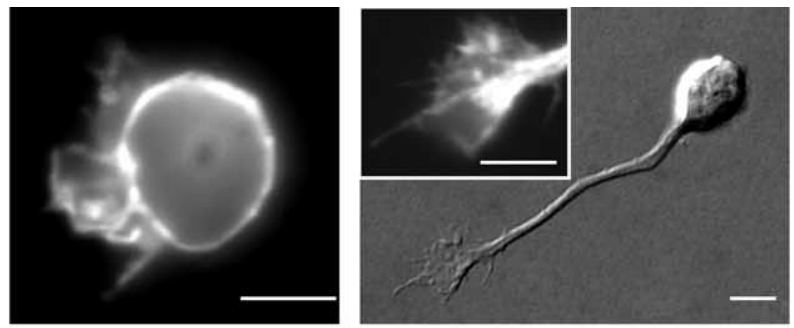

B Control 60h Bicuculline $20 \mu \mathrm{M} 60 \mathrm{~h}$ GABA $100 \mu \mathrm{M} 60 \mathrm{~h}$
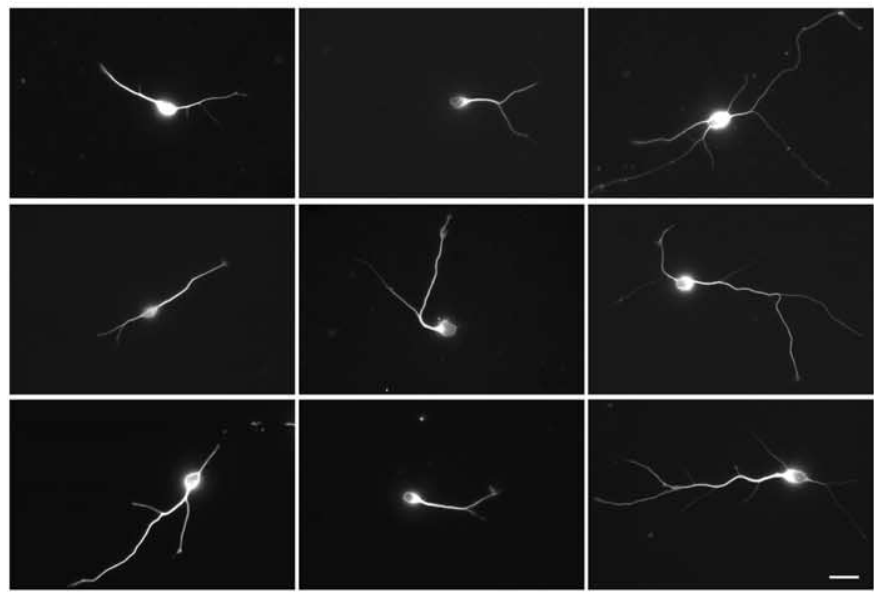

C
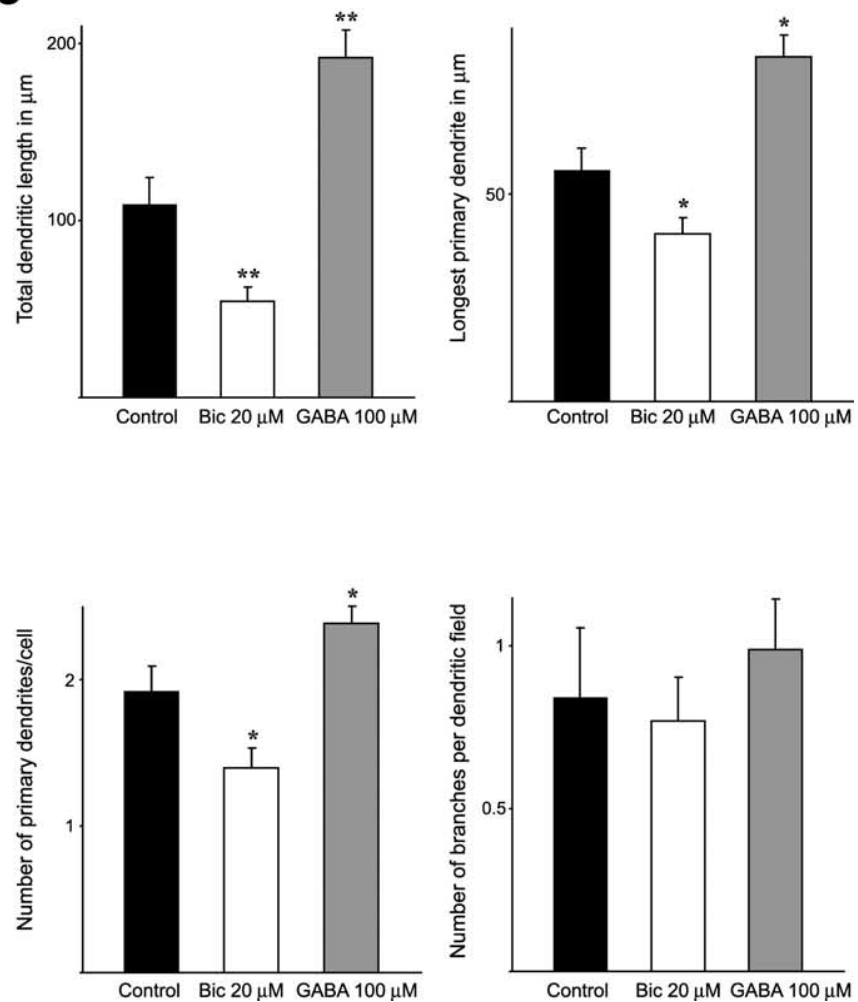

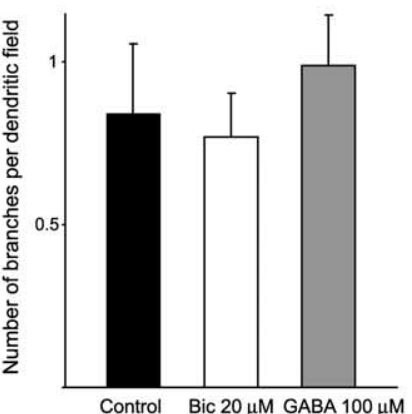

Figure 1. GABA $A_{A}$ activity controls early dendritic growth in cultured SVZ-derived neurons. A, Photographs illustrating the initial stages of dendritic development of cultured SVZ-derived cells. Six hours after plating, SVZ-derived cells exhibit a round shape and extend perisomal lamellipodia revealed by F-actin staining (left). By $24 \mathrm{~h}$ (right), most cells display a thin shaft tipped with an actin-rich growth cone (inset). Scale bar, $10 \mu \mathrm{m}$. B. Examples of cells illustrating the effects of treatment with bicuculline (20 $\mu \mathrm{m})$ and GABA (100 $\mu \mathrm{m})$ for $60 \mathrm{~h}$ after plating. Bicuculline induced a reduction in dendritic complexity compared with control cells. Conversely, cells treated with GABA exhibited an increased dendritic development. Scale bar, $20 \mu \mathrm{m}$. C, Quantification of the effect of $G A B A_{A}$ receptor blocking/activation on dendritic complexity at the early phase of culture. Dendritic length and the number of primary dendrites were significantly modified when cells were treated with bicuculline (Bic) or GABA. More than 500 cells were analyzed for each group in $n=3$ independent experiments. Error bars indicate SD. ${ }^{*} p<0.05$, ${ }^{* *} p<0.001$, Holm-Sidak test.

cells that had migrated from the subventricular zone and identify, through BrdU staining, the cells born at the same time. As illustrated in Figure $2 C$, in control slices, BrdU+/GFP+ neurons displayed typically a unipolar morphology with a single nonbranched dendrite oriented toward the pial surface. Approximately $40 \%$ of cells exhibited a second dendrite in the opposite direction. This morphology is characteristic of new neurons of the OB during early stages of development (Carleton et al., 2003). When slices were cultured with bicuculline $(20 \mu \mathrm{M})$ for $36 \mathrm{~h}$, the morphology of BrdU+/GFP + cells changed drastically (Fig. 2C). We observed a significant decrease in dendritic length, and substantially fewer cells exhibited a second primary dendrite (Fig. $2 D$ ). Similar to dissociated cultures, application of exogenous GABA $(100 \mu \mathrm{M})$ stimulated dendritic growth of new neurons in the OB (Fig. 2C). Most cells treated with GABA exhibited two primary dendrites and their length increased significantly (Fig. $2 D$ ). Interestingly, neurons at this stage of development exhibited very few branches and blocking/activating $\mathrm{GABA}_{\mathrm{A}}$ receptors did not affect this process (Fig. $2 C, D$ ). Thus, both ambient and exogenously applied GABA were able to regulate dendritic development of newly generated neurons in the environment of the olfactory bulb.

\section{$\mathrm{GABA}_{\mathrm{A}}$ signaling modulates lamellipodial dynamics in dendritic growth cones}

To further examine the cellular mechanisms underlying these effects of ambient GABA, we reverted to dissociated cultures at 1 DIV. At this stage, most of the cells exhibited a single dendritic process tipped with a growth cone that showed dynamic movements including rapid protrusions and retraction of lamellipodia and filopodia. The dendritic nature of these processes was confirmed by immunostaining for the dendritic marker MAP2 (microtubule-associated protein 2) at the end of the experiment. We observed that modulating $\mathrm{GABA}_{\mathrm{A}}$ activity by bicuculline or exogenous GABA altered growth cone morphology (Fig. $3 A$ ): in the presence of bicuculline, growth cones became smaller, whereas GABA induced the opposite effect.

To resolve the fine details of their motility, we performed time-lapse recordings at $1 \mathrm{~min}$ intervals. As illustrated in Figure 3, $B$ and $C$, and supplemental video 1 (available at www.jneurosci. org as supplemental material), exposure to bicuculline led to a significant decrease in the frequency and the surface area of lamellipodia. These changes were reversed by the subsequent application of GABA $(100 \mu \mathrm{M})$ in the presence of bicuculline (Fig. $3 B, C$; supplemental video 1 , available at www.jneurosci.org as supplemental material). Similar results were obtained using another $\mathrm{GABA}_{\mathrm{A}}$ antagonist, SR95531 $(40 \mu \mathrm{M})$ (data not shown). Interestingly, no changes in lamellipodia dynamics were observed after blocking $\mathrm{GABA}_{\mathrm{B}}$ (frequency, control, $0.65 \pm 0.15$; CGP54626, $0.64 \pm 0.14 ; p>0.7$; surface, control, $13.34 \pm 4.38$; CGP54626, $12.98 \pm 3.49 ; p>0.7$ ) or $\mathrm{GABA}_{\mathrm{C}}$ receptors (frequency, control, $0.66 \pm 0.22$; TPMPA, $0.68 \pm 0.14 ; p>0.4$; surface, control, $11.6 \pm 4.38$; TPMPA, $11.11 \pm 3.36$; $p>0.4$ ).

To determine whether the effects of $\mathrm{GABA}_{\mathrm{A}}$ signaling on lamellipodial morphology resulted from an increased rate of lamellipodia formation or enhanced lamellipodia stability, we used 
short-time recordings (200 s duration; $5 \mathrm{~s}$ interval). Under basal conditions, growth cones exhibited several cycles of lamellipodia formation and retraction (1.12 \pm 0.21 events $/ \mathrm{min} ; n=20$ cells) (supplemental videos 2 and 3, available at www. jneurosci.org as supplemental material). The lifetime of these lamellipodia was $42.18 \pm 22.33 \mathrm{~s}(n=20$ cells $)$. Compared with controls, bicuculline $(20 \mu \mathrm{M})$ did not change the rate of lamellipodia formation (1.08 \pm 0.42 events $/ \mathrm{min} ; n=10$ cells; $p=$ 0.7 ) (supplemental video 2, available at www.jneurosci.org as supplemental material). However, the lifetime of lamellipodia decreased by three times $(13.82 \pm 5.19 \mathrm{~s} ; n=$ 10 cells; $p<0.01$ ) (Fig. 3D; supplemental video 2 , available at www.jneurosci.org as supplemental material). In contrast, treatment with different doses of GABA (from 5 to $100 \mu \mathrm{M}$ ) triggered a dramatic increase in lamellipodia stability $(5 \mu \mathrm{M}$ GABA, $165.37 \pm 43.45 \mathrm{~s}, n=9$ cells; $20 \mu \mathrm{M} \mathrm{GABA}$, $182.91 \pm 28.36 \mathrm{~s}, n=8$ cells; $100 \mu \mathrm{M}$ GABA, $187.78 \pm 33.08$ s, $n=10$ cells; $p<$ 0.01 ) (Fig. 3D; supplemental video 3 , available at www.jneurosci.org as supplemental material), which in most cases remained present during the whole recording period. Neither bicuculline nor GABA treatment affected the number of filopodia or their rate of formation/retraction at the growth cone (data not shown) suggesting that modification of $\mathrm{GABA}_{\mathrm{A}}$ activity is not involved in growth cone filopodia dynamics. Interestingly, $\mathrm{GABA}_{\mathrm{A}}$ activity did not affect growth cone lamellipodia at a later phase of development (6 DIV) (Fig. 3E), clearly indicating the time specificity of this effect.

\section{$\mathrm{GABA}_{\mathrm{A}}$ activity promotes lamellipodia} formation of SVZ-derived neurons in the olfactory bulb

To explore the relevance of these findings in the $\mathrm{OB}$ context, we labeled newly generated neurons intraventricular injections of GFP-lentivirus. Eight days after infection, olfactory bulb slices were prepared and lamellipodia dynamics examined in situ (Fig. 4A). Because lamellipodia activity of GFP + cells under basal conditions was significantly less robust than in dissociated cells, we tested whether exogenously applied GABA can stimulate lamellipodia dynamics rather than blocking low basal levels of activity using bicuculline. Administration of GABA $(200 \mu \mathrm{M})$ induced a significant increase in the frequency of lamellipodia (from $2.12 \pm 0.55$ per imaging session to $8.27 \pm 0.7$; $n=33$ cells) (Fig. $4 B$ ). A total of 12 of these 33 cells did not present lamellipodia under basal conditions. Remarkably, GABA elicited the apparition of lamellipodia in all of these 12 cells. Finally, the subsequent application of bicuculline $(50 \mu \mathrm{M})$ led to a decrease in lamellipodia number to $1.7 \pm 0.39$ per imaging session ( $n=10$ cells) (Fig. $4 B)$.

A

C

D
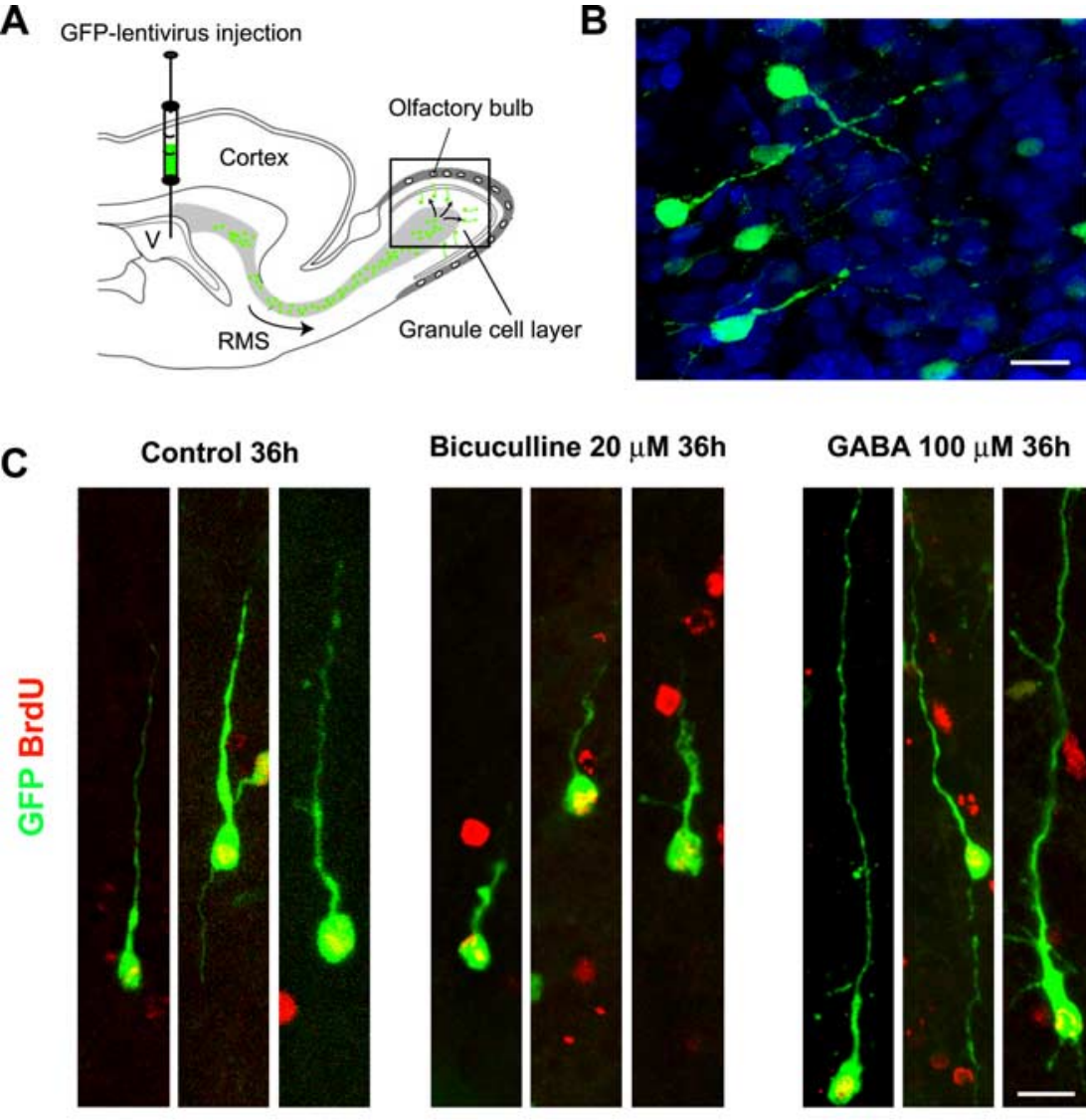

Bicuculline $20 \mu \mathrm{M} 36 \mathrm{~h}$
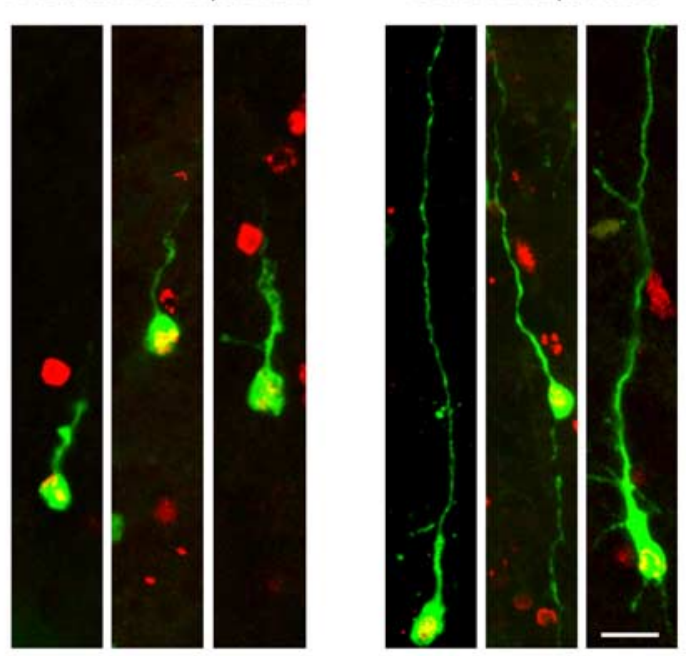

Figure 2. $G A B A_{A}$ receptor activation/blocking modifies dendritic growth of newly generated neurons in the olfactory bulb. $A$, Experimental protocol. After a GFP lentiviral injection into the lateral ventricle of newborn rats $(\mathrm{PO})$, animals received a single dose of BrdU (50 mg/kg) at P4 and sagittal slices of OB were prepared at P12 to study GFP + neuroblasts that, after migration, have reached the olfactory bulb. $B$, Confocal image showing GFP + neuroblasts in the granule cell layer after lentiviral injection in the lateral ventricle. C, Confocal images of double-labeled BrdU +/GFP + cells in the granule cell layer of olfactory bulb slices cultured $G_{A B A}$ activation/blocking. Scale bar, $20 \mu \mathrm{m}$. D, Quantification revealed that bicuculline (Bic) induced a significant increase in the number of primary dendrites (left) and the dendritic length (middle), whereas treatment with GABA had the opposite effects. Neither GABA nor bicuculline affected the number of branches (right). For this analysis, at least $100 \mathrm{BrdU}+/ \mathrm{GFP}+$ cells were
taken into account for each condition. Error bars indicate SD. ${ }^{*} p<0.05,{ }^{* *} p<0.001$, Holm-Sidak test.

We then repeated the same experiments using slices prepared $14 \mathrm{~d}$ after viral infection. GFP + cells in the granule layer exhibited a more mature morphology and were much less active. In these experiments, GABA/bicuculline failed to increase lamellipodia activity (data not shown), further confirming that it only affected neurons at early stages of development.

$\mathrm{GABA}_{\mathrm{A}}$ activity regulates stability and elongation of newly formed dendritic processes in culture

We next examined how these changes at the growth cone correlated to the growing behavior of developing dendrites. For that purpose, longer time-lapse recording was performed ( $5 \mathrm{~h}$ dura- 

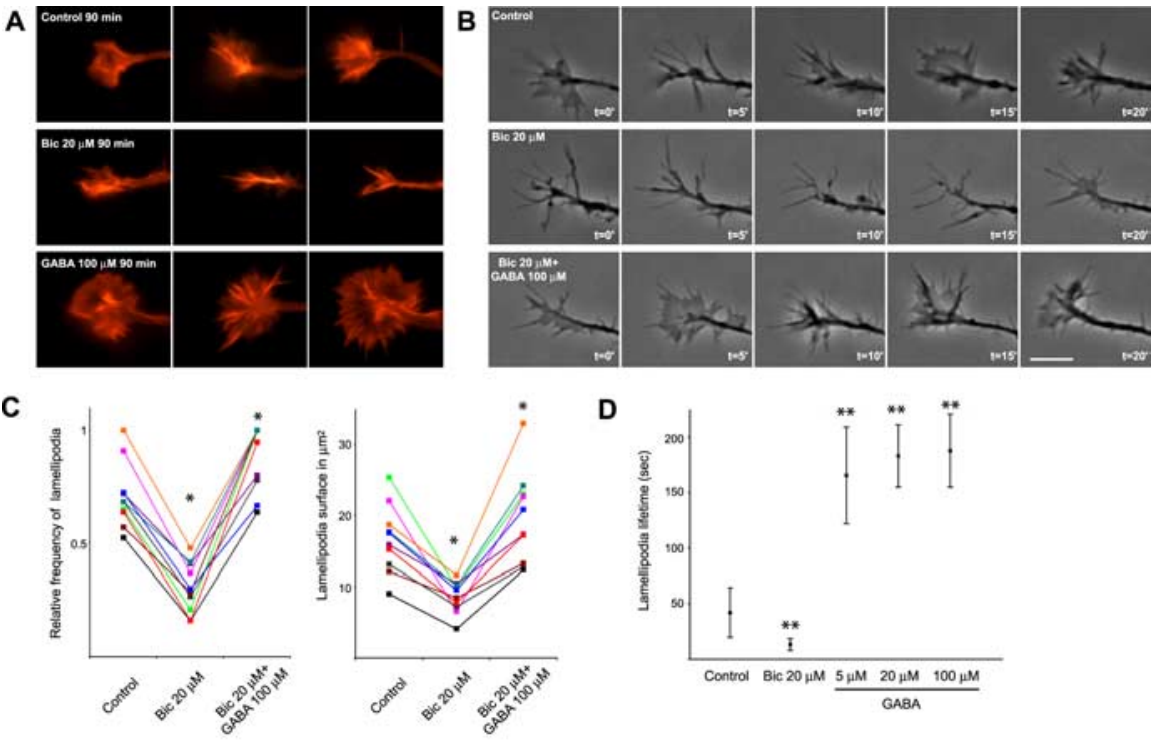

E

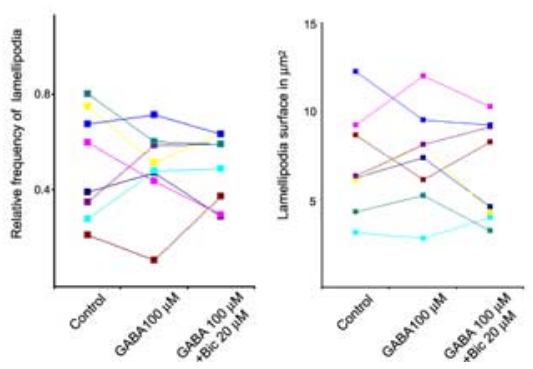

Figure 3. $G A B A_{A}$ activation/blocking modify lamellipodia dynamics at the growth cone. $A$, Representative examples of F-actin-stained growth cones of 1 DIV cells treated for 90 min with bicuculline (Bic) $(20 \mu \mathrm{m})$ or GABA (100 $\mu \mathrm{m})$. Growth cone surface caused by changes in lamellipodia was decreased in the presence of bicuculline. Conversely, GABA induced the enlargement of these protrusions. $\boldsymbol{B}$, Phase-contrast photos of time-lapse recordings showing the same representative growth cone (at 1 DIV) that was recorded under control conditions and after the sequential application of bicuculline $(20 \mu \mathrm{m})$ and GABA $(100 \mu \mathrm{M})$. Bicuculline induced a decreased presence of lamellipodia compared with control conditions. This effect was abolished after the administration of GABA. Scale bars, $10 \mu \mathrm{m}$. C, Quantification of the effect of GABA activation/blocking on lamellipodia in 1 DIV cells (each colored square represents the response of the same cell to the treatments) revealed that bicuculline induced a reduction in the frequency and the surface area of lamellipodia, whereas the subsequent application of $G A B A$ reversed these changes $\left({ }^{*} p<\right.$

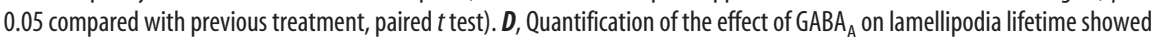
that bicuculline significantly affected lamellipodia stability. In contrast, exogenously applied GABA increased lamellipodia lifetime independently of the dose (** $p<0.01$ compared with control, paired $t$ test). Error bars indicate SD. $E$, Quantification of the effect of $\mathrm{GABA}_{\mathrm{A}}$ activation/blocking on lamellipodia in 6 DIV cells revealed that neither GABA nor bicuculline significantly modified lamellipodia dynamics at this later stage of maturation. ${ }^{*} p<0.05$, Holm-Sidak test.

tion; 10 min interval). These experiments confirmed the highly dynamic nature of early dendritic process, which repeatedly extended and retracted (Fig. $5 A, B$; supplemental video 4 , available at www.jneurosci.

org as supplemental material). Because the frequency and speed of elongation phases exceeded those of retraction, a net growth of dendrites occurred over the $5 \mathrm{~h}$ period $[119 \pm 13.99 \%$ of the initial length $\left(L_{0}\right) ; n=11$ cells] (Fig. $5 B$ ); average speed of elongation and retraction were $7.04 \pm 1.59$ and $6.21 \pm 1.64 \mu \mathrm{m} / \mathrm{h}$, respectively. Application of bicuculline resulted in highly unstable dendrites (Fig. $5 A, B$; supplemental video 5 , available at www.jneurosci.org as supplemental material) and led to an overall reduction in dendritic length ( $86.51 \pm 9.57 \%$ of initial length; control, $n=9 ; p<0.01$ ) (Fig. $5 B$ ). Our analysis revealed that bicuculline treatment specifically increased the frequency of retraction phases (control, 0.47 , vs bicuculline, 0.66 ; control, $n=11$ cells; bicuculline, $n=9$ cells; $p<0.001$ ) and enhanced the retraction speed (control, $6.21 \pm 1.64 \mu \mathrm{m} / \mathrm{h}$, vs bicuculline, $8.29 \pm 1.73 \mu \mathrm{m} / \mathrm{h}$; control, $n=11$ cells; bicuculline, $n=$ 9 cells; $p<0.001$ ) (Fig. 5C). These results clearly indicate that local release of GABA plays a key role in stimulating dendritic elongation by stabilizing newly formed segments.

As illustrated in Figure 5, $A$ and $B$, and supplemental video 6 (available at www. jneurosci.org as supplemental material), GABA treatment $(100 \mu \mathrm{M})$ significantly increased the forward advance of the dendritic process leading to a $178 \pm 21.4 \%$ increase in length $(n=9 ; p<0.001)$ (Fig. $5 B)$. Quantitative analysis indicated that this increase was related to a decreased frequency (control, 0.47, vs GABA, 0.23; $p<$ 0.001 ; control, $n=11$ cells; GABA, $n=9$ cells) as well as in the speed of retraction phases (control, $6.21 \pm 1.64 \mu \mathrm{m} / \mathrm{h}$, vs GABA, $3.25 \pm 1.53 \mu \mathrm{m} / \mathrm{h}$; control, $n=11$ cells; GABA, $n=9$ cells; $p<0.001$ ) (Fig. $5 C$ ). In five of nine cells, GABA promoted the stabilization of one of the small protrusions around the cell body leading to the formation of a second primary dendrite (supplemental video 7, available at www. jneurosci.org as supplemental material). None of the control cells $(n=11)$ exhibited a similar behavior during the $5 \mathrm{~h}$ observation period, raising the possibility that $\mathrm{GABA}_{\mathrm{A}}$ activation might promote dendritic initiation by favoring the rapid stabilization of new dendritic process.

\section{$\mathrm{GABA}_{\mathrm{A}}$ activity-induced dendritic growth is correlated with increased} stability of microtubules

Previous work has pointed to the importance of microtubules in dendritic stabilization and growth (Henley and Poo, 2004). To test whether microtubules were involved in the stabilization of primary dendrites and new dendritic segments induced by ambient GABA, we investigated whether bicuculline/GABA changed the proportion of polymerized versus nonpolymerized tubulin, as described previously (Vaillant et al., 2002). As shown in Figure 6, $24 \pm 0.86 \%$ of tubulin $(n=3)$ was polymerized under basal conditions. In cells treated with bicuculline for $6 \mathrm{~h}$, the proportion of polymerized tubulin decreased significantly $(13 \pm 1.36 \%$; $p<0.05)$, whereas GABA had the opposite effect $(50.9 \pm 6.38 \% ; p<0.05)$, suggesting that $\mathrm{GABA}_{\mathrm{A}}$ signaling modulates microtubule stability and thus controls stabilization of developing dendrites.

\section{GABA depolarizes and opens L-type voltage-gated calcium channels in SVZ-derived neurons during early phases of dendritic development}

The specific effects of GABA during the early stages of development but not later (after 5 DIV) raised the possibility that this was caused by a switch in $\mathrm{GABA}_{\mathrm{A}}$ responses from a depolarization to a hyperpolarization. We first tested the presence of functional $\mathrm{GABA}_{\mathrm{A}}$ receptors on cultured SVZ-derived neurons using wholecell patch-clamp recordings (holding potential, $-60 \mathrm{mV}$ ). Local application of GABA $(100 \mu \mathrm{M})$ elicited an inward current, rapid in onset, in almost all tested cells ( 1 DIV, $n=11$ of $11 ; 6$ DIV, $n=$ 
18 of 19) (Fig. 7A). The intensity of responses was variable from cell to cell. The mean current intensity was $-697 \pm 244$ $\mathrm{pA}$ (range, -106 to $-2070 \mathrm{pA}$ ) for $1 \mathrm{DIV}$ cells, and $-988 \pm 262 \mathrm{pA}$ (range, -130 to $-2500 \mathrm{pA}$ ) for 6 DIV cells. GABA responses were completely and reversibly blocked in the presence of $20 \mu \mathrm{M}$ bicuculline ( $1 \mathrm{DIV}, n=3$; $6 \mathrm{DIV}, n=5$; percentage of blockade, $95 \pm 3 \%$ ) (Fig. $7 A$ ) but remained unaffected by the application of the GABA $_{\mathrm{C}}$ antagonist TPMPA $(20 \mu \mathrm{M})(1$ DIV, $n=3 ; 6$ DIV, $n=3)$. The mean resting potential of cells was $-25 \pm 3 \mathrm{mV}$ ( $n=6$ cells) (ranging from -18 to -40 $\mathrm{mV}$ ); we detected no difference between 1 and 6 DIV cells. These results confirmed that SVZ-derived neurons expressed $\mathrm{GABA}_{\mathrm{A}}$ receptors from early immature stages (Stewart et al., 2002; Carleton et al., 2003).

During neuronal development, a switch in $\mathrm{GABA}_{\mathrm{A}}$ responses from depolarization to hyperpolarization (Belluzzi et al., 2003; Carleton et al., 2003; Ge et al., 2006) has been linked to a decrease in $\left[\mathrm{Cl}^{-}\right]_{\mathrm{i}}$ (Ben-Ari, 2002). The specific effects of GABA during the early stages of development but not later (after 5 DIV) raised the possibility that this was attributable to this switch. To examine this possibility, we performed gramicidin-perforated patchclamp recordings. The mean GABA membrane responses obtained in such conditions were comparable with $\mathrm{GABA}_{\mathrm{A}}$ currents obtained in whole-cell experiments for 1 DIV cells (mean intensity, $-538 \pm 177 \mathrm{pA}$; range, -38 to -1410 $\mathrm{pA}$ ), and somewhat smaller (although not significantly) for 6 DIV cells (mean intensity, $-580 \pm 166 \mathrm{pA}$; range, -20 to -2235 $\mathrm{pA})$. We found that the mean $E_{\mathrm{GABA}}$ was significantly more negative in 6 DIV SVZderived neurons $(-34 \pm 10 \mathrm{mV} ; n=7)$ than in 1 DIV cells $(-17 \pm 2 \mathrm{mV} ; n=3$; $\left.\chi^{2}=0.005\right)($ Fig. $7 B)$. The calculated $\mathrm{Cl}^{-}$i concentration was $79 \pm 6 \mathrm{mM}$ for 1 DIV cells and $40 \pm 2 \mathrm{~mm}$ for 6 DIV cells, indicating a progressive shift toward hyperpolarization with development of cultured SVZ-derived neurons. This was further confirmed by the analysis of the expression pattern of $\mathrm{K}^{+} / \mathrm{Cl}^{-}$cotransporter KCC2 by real-time RT-PCR. We found that KCC2 mRNA progressively increased during maturation, cultures displaying nearly 25 times higher mRNA expression at 6 DIV than 1 DIV cells (Fig. 7C). Consistent with this, KCC2 immunoreactivity was nearly absent during the first $2 \mathrm{~d}$ in culture but increased progressively later on and was clearly visible in 6 DIV cells (Fig. 7D), correlating with the changes in GABA equilibrium potential and $\mathrm{Cl}^{-}{ }_{i}$ concentrations (Rivera et al., 1999).

To further test whether this change in $\mathrm{GABA}_{\mathrm{A}}$ responses led to a shift from depolarization to hyperpolarization, we used calcium

A

B
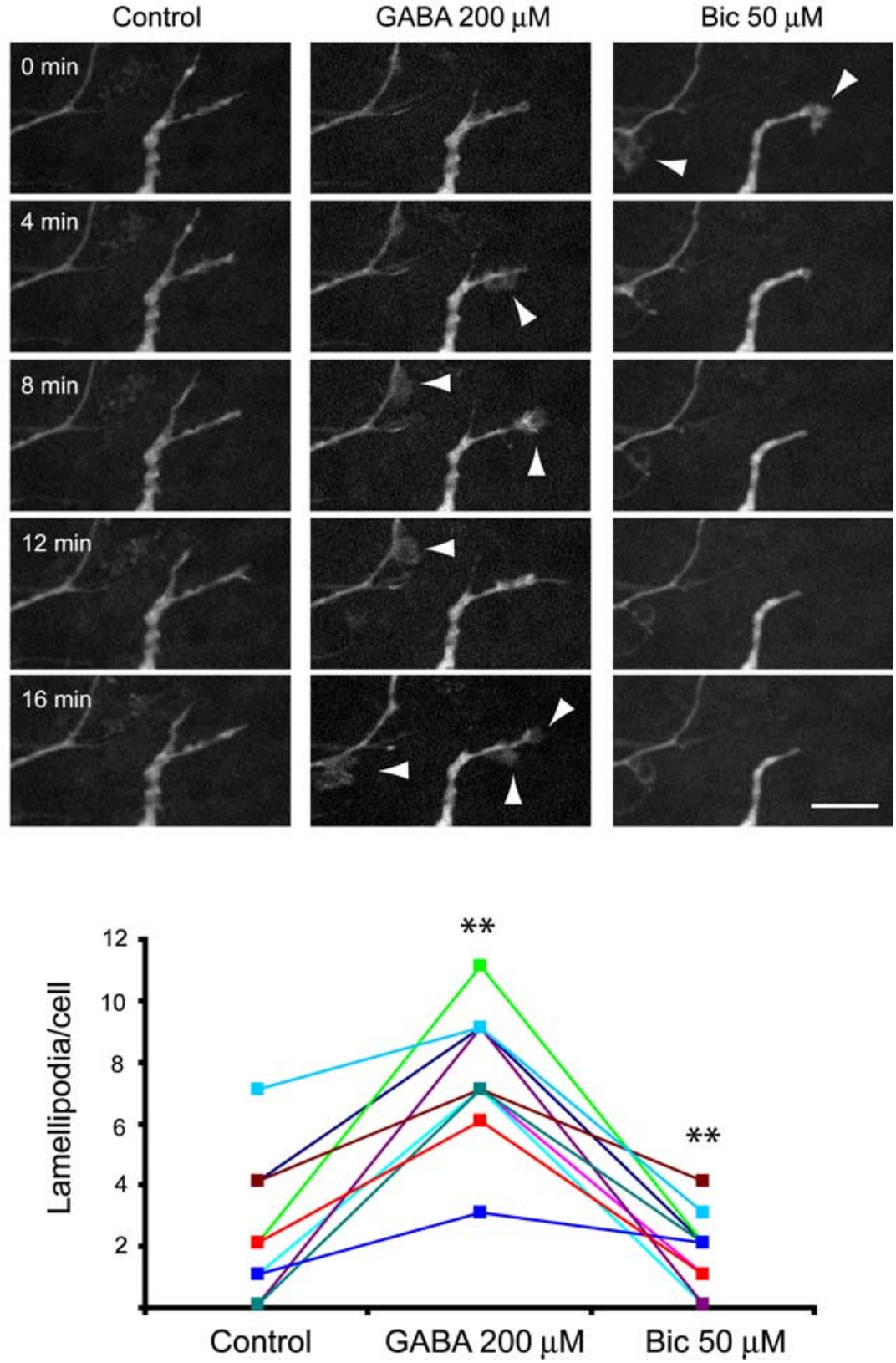

Figure 4. Lamellipodia dynamics of newborn neurons in the $O B$ are affected by $G A B A_{A}$ activity. $A$, Confocal $z$-stack projection images taken from a time-lapse recording of GFP + neuroblasts located in the granule cell layer. The same field was observed under control conditions followed by GABA $(200 \mu \mathrm{m})$ and bicuculline (Bic) $(50 \mu \mathrm{m})$ application. New lamellipodia were induced by GABA application (arrowheads), whereas bicuculline treatment led to the progressive disappearance of nearly all lamellipodia activity. Scale bars, $10 \mu \mathrm{m}$. B, Quantification of the effect of $\mathrm{GABA}_{A}$ activation/blocking on lamellipodia in $0 \mathrm{~B}$ slices revealed that GABA induced a significant increase in the frequency of lamellipodia, whereas bicuculline elicited the opposite effects. ${ }^{* *} p<0.01$ compared with previous treatment, paired $t$ test.

imaging. We found that a brief exposure (10-30 s) to GABA at different concentrations induced a transitory increase in $\left[\mathrm{Ca}^{2+}\right]_{\mathrm{i}}$ in $\sim 75 \%$ of 1 DIV cells ( 14 of 18 cells) (Fig. $7 E$ ). This response was bicuculline-sensitive and thus mediated through $\mathrm{GABA}_{\mathrm{A}}$ receptors ( 7 of 8 cells) (Fig. $7 E$ ). No such response was observed in more mature neurons (6 DIV; 0 of 9 cells) (Fig. $7 F$ ). However, calcium transients were easily elicited by glutamate application in 6 DIV cells (Fig. 7F).

We next investigated the source of calcium required for the effects of GABA. We found that exposure to $1 \mu \mathrm{M}$ nifedipine (L-type $\mathrm{Ca}^{2+}$ channels blocker) before GABA prevented the cal- 
A
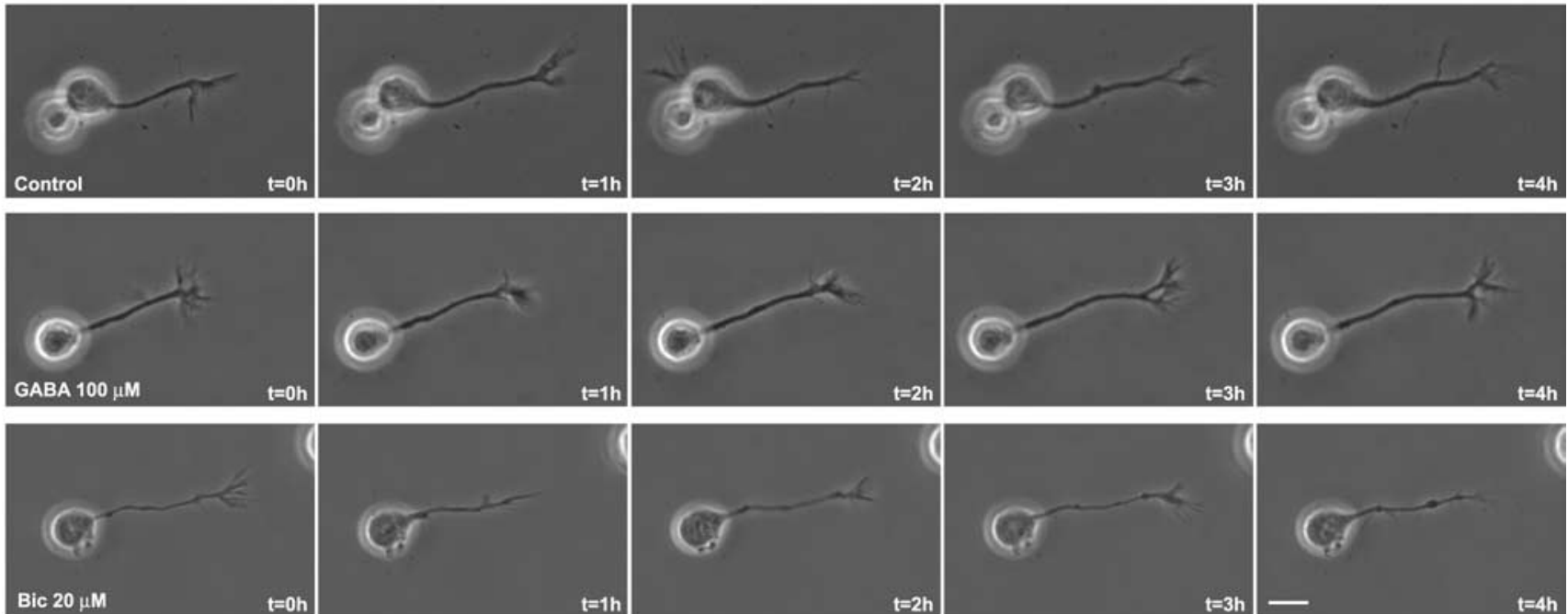

B
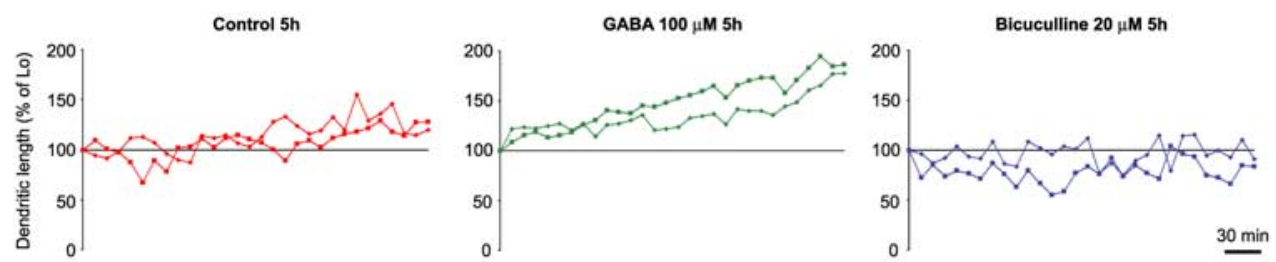

C

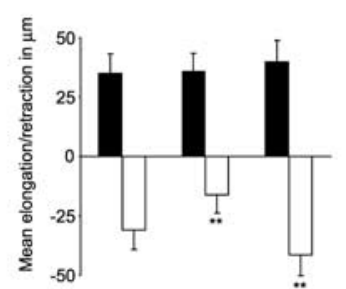

Control GABA100 $\mu \mathrm{M}$ Bic $20 \mu \mathrm{M}$

Figure 5. $G A B A_{A}$ activation regulates dendritic elongation. $A$, Representative phase-contrast photos of time lapse experiments in which 1 DIV cells were recorded for $5 \mathrm{~h}$ under control conditions or in the presence of bicuculline (Bic) (20 $\mu \mathrm{M})$ or GABA $(100 \mu \mathrm{m})$. Control cells exhibited alternative phases of elongation and retraction leading to net growth after $5 \mathrm{~h}$. Bicuculline administration resulted in highly unstable dendrites that grew and retracted at similar rates, whereas treatment with GABA promoted elongation by decreasing the frequency of retraction phases. Scale bars, 10 $\mu \mathrm{m}$. $\boldsymbol{B}$, Dendritic length, expressed as a percentage of the initial length $\left(L_{0}\right)$, is plotted against time to visualize the effect of $G A B A_{A}$ activation/blocking. Two representative examples are illustrated for each treatment. GABA induced a significant increase in dendritic length, whereas bicuculline reduced dendritic length. $C$, Quantitative analysis of the mean elongation/retraction of $>30$ cells reveals a significant increase of retraction in cells treated with bicuculline, whereas a decrease was detected after GABA. Error bars indicate SD. ${ }^{* *} p<0.001, \mathrm{Holm}-\mathrm{Sidak}$ test.

cium increase (6 of 6 cells) (Fig. $7 G)$. Either mibefradil (T-type $\mathrm{Ca}^{2+}$ channels blocker; 0 of 4 cells; $p>0.7$ ) and ryanodine (an inhibitor of calcium release from internal stores; 1 of 11 cells; $p>$ 0.4 ) failed to inhibit GABA-mediated calcium responses, thus clearly pointing to the importance of L-type voltage-gated calcium (VGC) activation by GABA-induced depolarization. Consistent with these observations, the effect of GABA on lamellipodia dynamism required the presence of calcium, because GABA was no longer able to induce any change in the growth cone in the presence of the calcium chelator BAPTA-AM (200 nM) or the L-type $\mathrm{Ca}^{2+}$ channels blocker nifedipine $(1 \mu \mathrm{M})$ (supplemental Fig. 2, available at www.jneurosci.org as supplemental material).

\section{$\mathrm{GABA}_{\mathrm{A}}$ receptors in SVZ-derived neurons are slowly desensitizing}

Persistent activation of different types of $\mathrm{GABA}_{\mathrm{A}}$ receptors could lead to their desensitization. Because many of our experiments were performed in the continuous presence of GABA, we sought to examine desensitization in SVZ-derived neurons. Interestingly, the effects of different doses of GABA on lamellipodia stability (see above) were not significantly different, suggesting that SVZ-derived neurons displayed high affinity and low desensitizing $\mathrm{GABA}_{\mathrm{A}}$ receptors. To further explore this issue, cells were cultured in the presence of GABA $(100 \mu \mathrm{M})$ for $24 \mathrm{~h}$, and then challenged with another dose of GABA $(100 \mu \mathrm{M})$. We observed that GABA reapplication still triggered calcium rises (Fig. $7 \mathrm{H})(5$ of 7 cells), suggesting that SVZ-derived neurons might express specific subsets of $\mathrm{GABA}_{\mathrm{A}}$ receptors characterized by low levels of desensitization. Moreover, these calcium responses (measured as the percentage of increase from the baseline) were not quantitatively different from those detected in cells that have not been exposed to GABA (control, $86 \pm 19.6 \%, n=18$; GABA reapplication, $95 \pm 28.6 \%, n=7 ; p>0.3)$. We next examined how the continuous presence of GABA in the culture medium influenced $\mathrm{Ca}_{\mathrm{i}}$ levels. We found that, during a $40-60$ min observation period, a single administration of GABA was able to induce recurring calcium transients (Fig. 7I) $(n=4$ cells). These calcium currents relied on $\mathrm{GABA}_{\mathrm{A}}$ receptors because they were specifically blocked by bicuculline (Fig. 7I). Together, these results indicate that $\mathrm{GABA}_{\mathrm{A}}$ receptors in SVZ-derived neurons exhibit only a limited degree of desensitization, allowing these cells to persistently respond to GABA. Because GABA effects on lamellipodial dynamics were abolished by the application of the calcium chelator BAPTA-AM or nifedipine (supplemental Fig. 2, available at www.jneurosci.org as supplemental material), our data also suggest that recurrent calcium transients generated by ambient GABA might be important for the proper dynamic of dendritic growth cones and dendritic elongation.

\section{Discussion}

Extrasynaptic $\mathrm{GABA}_{\mathrm{A}}$ receptor activity is the first neurotransmitter-related signaling mechanisms exhibited by newborn neurons from the subventricular zone when they migrate toward the OB (Belluzzi et al., 2003; Carleton et al., 2003). Here, we 

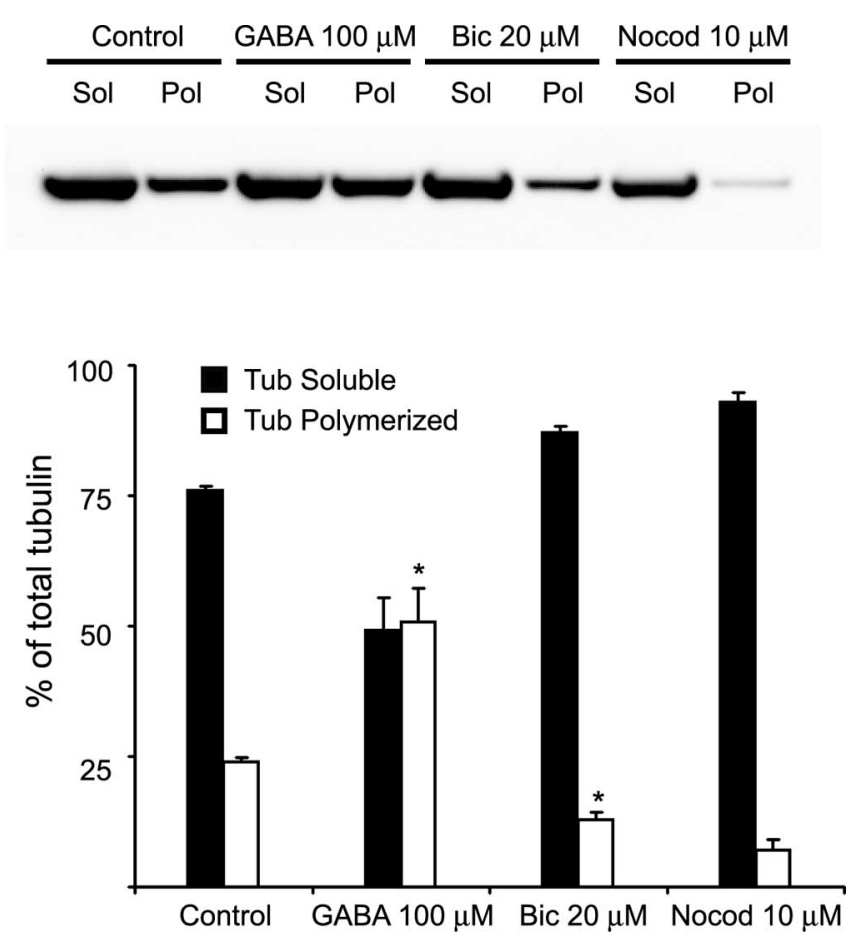

Figure 6. $\mathrm{GABA}_{\mathrm{A}}$ activation/blocking affects microtubule stability. After $6 \mathrm{~h}$ of treatment with control medium, GABA (100 $\mu \mathrm{m})$, or bicuculline (20 $\mu \mathrm{M})$, cells were lysed and the soluble nonpolymerized tubulin was extracted. Microtubules were then depolymerized and tubulin monomers were isolated. Both fractions (soluble and polymerized) were resolved by Western blotting (top), quantified, and compared after different treatments (bottom). The results show that GABA consistently increased the polymerized fraction, suggesting an enhanced stability of microtubules. In contrast, bicuculline application resulted in a higher proportion of the soluble fraction. The microtubule depolymerizing activity of nocodazole $(10 \mu \mathrm{m})$ was used as internal control. Error bars indicateSD. ${ }^{*} p<0.05$, Holm-Sidak test. Bic, Bicuculline; Nocod, nocodazole; Pol, polymerized; Sol, soluble; Tub, tubulin.

provide evidence that ambient GABA is required for the adequate initiation of dendritic growth, a crucial step in the integration process of neuronal progenitors in olfactory networks. We describe, for the first time, that $\mathrm{GABA}_{\mathrm{A}}$ activity promotes the stabilization of lamellipodia on dendritic growth cones, thereby regulating the elongation of newly formed primary dendrites. This process is associated with an increased stability of microtubules and depends on depolarization and calcium influx.

Previous studies demonstrated that during development GABA acting as an excitatory neurotransmitter stimulates dendritic growth in immature neurons (Represa and Ben-Ari, 2005). A recently published work has established that depolarizing GABA activity is also required for the appropriate dendritic development of newborn neurons generated in the adult hippocampus (Ge at al., 2006). Our findings lend strong support to this notion by demonstrating a similar role for ambient GABA in the OB. In addition, they provide an insight into the cellular basis underlying this effect that had not been explored previously. We show that the specific function of ambient GABA during initial stages of dendritic development is to increase the temporal stability of lamellipodia without affecting filopodia formation. Lamellipodia are known to play a crucial role in growth cone motility (Dickson, 2002). Thus, it has been proposed that lamellipodia might help to stabilize growth cones and promote neurite elongation (Wayman et al., 2004). Consistent with this idea, we found that GABA promotes stabilization of newly formed dendritic segments, thereby inducing a net elongation of dendrites.
Furthermore, GABA favors the rapid stabilization of thin processes emerging from the cell body, leading in this way to the formation of a new primary dendrite. Thus, our detailed analysis of the growing behavior of dendrites has demonstrated for the first time that $\mathrm{GABA}_{\mathrm{A}}$ activity specifically prevents the retraction process in developing dendrites. Collectively, these results raise the intriguing possibility that ambient GABA, present in the cellular environment of newborn neurons, maintains tonic activation of $\mathrm{GABA}_{\mathrm{A}}$ receptors that, in turn, might be crucial for the stabilization of newly formed process and therefore to ensure the adequate initiation and elongation of dendrites. This hypothesis received strong support from our observations with calcium imaging demonstrating that $\mathrm{GABA}_{\mathrm{A}}$ receptors present on these cells are able to respond tonically to GABA. Hence, similar to neurons in the hippocampus and the cerebellum (Brickley et al., 1996; Hamann et al., 2002; Nusser and Mody, 2002), subventricular zone-derived neurons may express $\mathrm{GABA}_{\mathrm{A}}$ receptors that are persistently open and slowly desensitizing. The idea of tonic activation of $\mathrm{GABA}_{\mathrm{A}}$ receptors through autocrine/paracrine signaling loop in SVZ cells is in line with previous reports showing that newly generated neurons are able to produce and spontaneously liberate GABA (Bolteus and Bordey, 2004; Bolteus et al., 2005).

Previous work provided estimates of GABA concentration in dissociated cultures (micromolar range) (Waagepetersen et al., 2003; Sonnewald et al., 2006) or in slice preparations (1-3 $\mu \mathrm{M})$ (Bolteus et al., 2005). It is noteworthy that these physiological concentrations of GABA could be significantly higher at the cell membrane because GABA could act through an autocrine/paracrine loop. In the current studies, we have demonstrated that GABA in concentrations as low as $1 \mu \mathrm{M}$ could elicit calcium responses in SVZ generated neurons. Moreover, we showed that application of GABA at $5 \mu \mathrm{m}$ concentration induces a substantial increase in lamellipodia stability, and this effect did not differ from that we observe in the presence of $100 \mu \mathrm{M}$ GABA. Finally, we demonstrate, using calcium imaging, that $\mathrm{GABA}_{\mathrm{A}}$ receptors present on these cells are able to respond tonically to GABA (100 $\mu \mathrm{M})$. Therefore, we believe that the effects of GABA demonstrated in the current study are physiologically relevant. It remains that, in some experiments, we used higher doses of GABA. In accordance with previous reports (Bird and Owen, 1998; Borodinsky et al., 2003), we had to take into consideration the possibility of a rapid GABA degradation and used relatively high concentrations of GABA $(100 \mu \mathrm{M})$ for chronic treatment experiments $(>5 \mathrm{~h})$. Similarly, in slice cultures, high doses were required for inducing lamellipodia on a timescale similar to that of dissociated cultures. This probably reflects limitations in the diffusion of GABA through the slice as well as the uptake of GABA by glial cells. The same situation holds true for glutamate that is to be applied in the millimolar range to affect excitatory transmission in slice preparations.

An important new observation of the current study is that $\mathrm{GABA}_{\mathrm{A}}$ activity affects microtubule stability. Because microtubules are known to play an essential role in dendritic stability (Bray et al., 1978; Dehmelt et al., 2003; Henley and Poo, 2004; Suter et al., 2004), these results nicely correlate to the observed behavior of developing dendrites in our recordings. They are also consistent with previous reports suggesting that microtubules drive growth cone steering (Suter et al., 2004) and the forward momentum of newly formed protrusions (Baas and Ahmad, 2001). $\mathrm{GABA}_{\mathrm{A}}$-mediated increase in microtubule stability most likely involves the activation of small GTPases such as Rac, which is known to be under the regulatory influence of intracellular calcium transients (Price et al., 2003). Interestingly, Diefenbach 

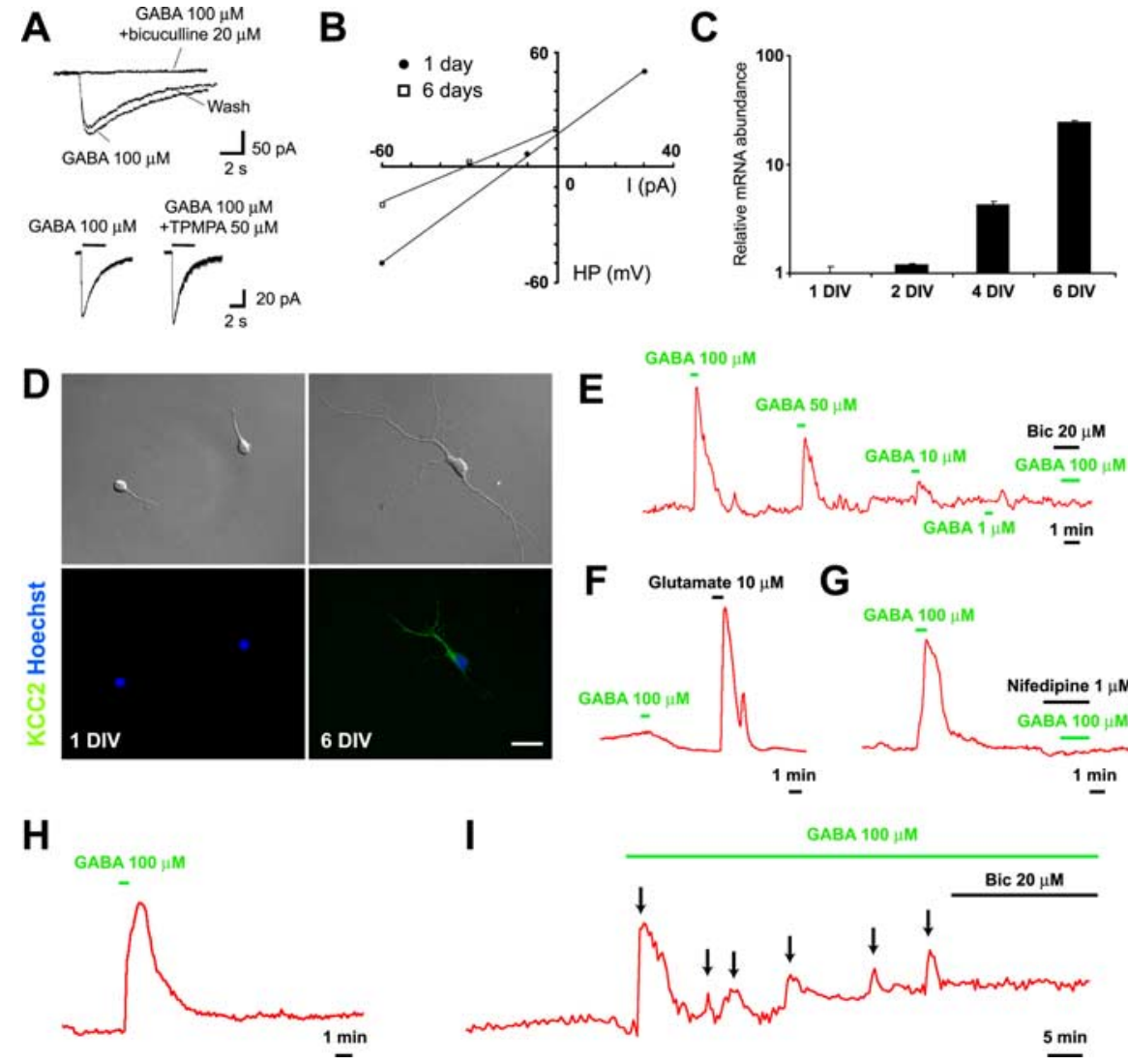

I
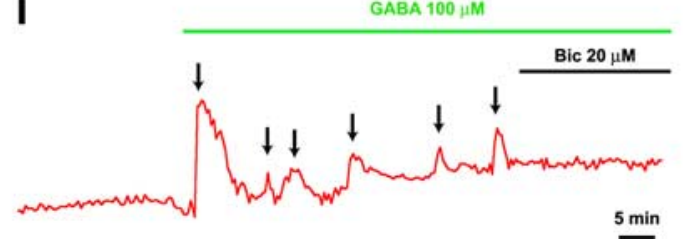

Figure 7. Developmental shift of GABA responses in SVZ-derived neurons in vitro. $\boldsymbol{A}$, Patch clamp under whole-cell configuration revealed that GABA (100 $\mu \mathrm{m}$ ) elicited an inward current blocked by bicuculline ( $20 \mu \mathrm{m})$ (top trace) but not by TPMPA (20 $\mu \mathrm{m})$ (bottom trace). B, I-V plotting of SVZ-derived neurons at different culture times. Gramicidin-perforated patch clamp was used to calculate $\mathrm{GABA}$ reversal potential $\left(E_{\mathrm{GABA}}\right)$. This analysis showed that $E_{\mathrm{GABA}}$ in $1 \mathrm{DIV}$ cells was significantly higher than in 6 DIV cells. C, Quantification of mRNA levels using real-time PCR demonstrated that KCC2 was dramatically upregulated along with the time in culture. $\beta$-Actin was used as reference gene. Error bars indicate SD. D, Representative examples of KCC2 immunoreactivity in SVZ-derived neurons at 1 and 6 DIV. To appreciate the differences in intensity, photographs were taken at the same time and using the same acquisition settings. Scale bars, $20 \mu \mathrm{m}$. $\boldsymbol{E}-\mathbf{G}$, Calcium responses after GABA stimulation. In 1 DIV cells loaded with the calcium sensitive dye fura-2, GABA elicited a dose-dependent increase in $\mathrm{Ca}_{\mathrm{i}}$ concentration that was abolished in the presence of bicuculline (Bic) $(20 \mu \mathrm{M})(\boldsymbol{E})$. Conversely, 6 DIV cells exhibited no change after GABA (100 $\mu \mathrm{m}$ ) application but responded to low doses of glutamate $(10 \mu \mathrm{m})(\boldsymbol{F})$. GABA responses in 1 DIV cells were dependent on the opening of L-type $\mathrm{Ca}^{2+}$ channels, because they were inhibited by a pretreatment with nifedipine $(1 \mu \mathrm{m})(\boldsymbol{G})$. $\boldsymbol{H}, \boldsymbol{I}$, Calcium responses after chronic GABA stimulation. GABA reapplication (100 $\mu \mathrm{m}$ ) elicited calcium transients in cells that have been cultured in the presence of GABA for $24 \mathrm{~h}(\boldsymbol{H})$. SVZderived neurons exhibited recurring calcium responses when GABA (100 $\mu \mathrm{m})$ was continuously present in the medium. These calcium oscillations were blocked by bicuculline $(I)$.

et al. (2002) reported that inactivation of myosin II resulted in changes in lamellipodia dynamics that very much resemble those observed here after the application of bicuculline: a rapid reduction of lamellipodia protrusions at the growth cone without affecting filopodia dynamics. They also show that the prolonged inhibition of lamellipodia protrusions leads to a significant reduction of neurite length. Thus, myosin II modulated by calcium signals could also represent another interesting downstream effector of GABA signaling.

The effects of $\mathrm{GABA}_{\mathrm{A}}$ activation are restricted to the initial stages of dendritic development in the OB. Our results strongly suggest that this is attributable to depolarization and activation of VGC channels. These findings lend support to the hypothesis of Ben-Ari (Ben-Ari, 2002; Represa and Ben-Ari, 2005) that GABA acts as a trophic factor to stimulate dendritic arbor development before the onset of inhibitory synaptogenesis. They are also in line with previous hypothesis proposing that there might be a "set point" of intracellular calcium that is ideal for growth cone mo- tility and neurite elongation (Kater et al., 1988). Below or above this optimal concentration, there is no longer a steering of growth cones and neurites may retract, as indeed observed in some experiments (Mattson et al., 1988). Our findings raise the possibility that GABA signaling during early dendritic development may provide the optimal changes in calcium required for growth cone motility and process elongation. However, it should be noted that GABA might not represent the only calcium generator because blocking $\mathrm{GABA}_{\mathrm{A}}$ receptor activity did not completely abolish lamellipodia activity and dendritic growth. Candidate molecules that could be involved in this process include neurotrophins (Gehler et al., 2004) and integrins (Bonner and O'Connor, 2001).

The physiological significance of our findings remains to be determined. Previous work demonstrated that GABA is involved in the control of $\mathrm{OB}$ neurogenesis by regulating proliferation and migration of neuronal precursors in the rostral migratory stream (Bolteus and Bordey, 2004; Liu et al., 2005). Our findings extend the role of GABA to the control of dendritic initiation. We propose that one of the main functions of GABA is to provide optimal membrane depolarization to trigger the changes in intracellular calcium concentrations required for the fine tuning of initial dendrite elongation and stabilization. We speculate that this effect of GABA would mainly be operative when SVZ precursors reach the $\mathrm{OB}$. In the migratory zone, efficient uptake mechanisms are believed to maintain ambient GABA at low levels, thereby preventing premature differentiation of neuroblasts (Bolteus and Bordey, 2004). After arriving in the OB granule cell layer, these cells are most likely to be exposed to an increased ambient GABA that is provided by neighboring GABAergic neurons taking part in active olfactory circuits. We suggest that locally released GABA along with the first GABAergic synaptic inputs (Carleton et al., 2003) may play a key role in signaling that favors the immobilization and differentiation of neuroblasts. An important aspect of such a mechanism would be that neuroblast differentiation and dendritic initiation driven by GABA could be coupled to olfactory network activity (Saghatelyan et al., 2005). An important recently published study demonstrates that indeed ambient GABA excites newly generated neurons in the hippocampus and regulates dendritic development and the synaptic integration of these cells (Ge et al., 2006). Because dendritic initiation is a crucial step for the process of synaptic integration, our results complement and extend these observations by offering a potential mechanism through which GABA may modulate this integration process. Given that GABAmediated depolarization and calcium signals have been implicated in the development of different systems (Henley and Poo, 2004; Represa and Ben-Ari, 2005), it is possible that the role we 
identified here for GABA represents a more general mechanism for regulating early dendritogenesis and neuronal integration.

\section{References}

Alvarez-Buylla A, Garcia-Verdugo JM (2002) Neurogenesis in adult subventricular zone. J Neurosci 22:629-634.

Baas PW, Ahmad FJ (2001) Force generation by cytoskeletal motor proteins as a regulator of axonal elongation and retraction. Trends Cell Biol 11:244-249.

Belluzzi O, Benedusi M, Ackman J, LoTurco JJ (2003) Electrophysiological differentiation of new neurons in the olfactory bulb. J Neurosci 23:10411-10418.

Ben-Ari Y (2002) Excitatory actions of gaba during development: the nature of the nurture. Nat Rev Neurosci 3:728-739.

Bird M, Owen A (1998) Neurite outgrowth-regulating properties of GABA and the effect of serum on mouse spinal cord neurons in culture. J Anat 193:503-508.

Bolteus AJ, Bordey A (2004) GABA release and uptake regulate neuronal precursor migration in the postnatal subventricular zone. J Neurosci 24:7623-7631.

Bolteus AJ, Garganta C, Bordey A (2005) Assays for measuring extracellular GABA levels and cell migration rate in acute slices. Brain Res Brain Res Protoc 14:126-134.

Bonner J, O’Connor TP (2001) The permissive cue laminin is essential for growth cone turning in vivo. J Neurosci 21:9782-9791.

Borodinsky LN, O’Leary D, Neale JH, Vicini S, Coso OA, Fiszman ML (2003) GABA-induced neurite outgrowth of cerebellar granule cells is mediated by $\operatorname{GABA}(\mathrm{A})$ receptor activation, calcium influx and CaMKII and erk1/2 pathways. J Neurochem 84:1411-1420.

Bray D, Thomas C, Shaw G (1978) Growth cone formation in cultures of sensory neurons. Proc Natl Acad Sci USA 75:5226-5229.

Brickley SG, Cull-Candy SG, Farrant M (1996) Development of a tonic form of synaptic inhibition in rat cerebellar granule cells resulting from persistent activation of GABAA receptors. J Physiol (Lond) 497:753-759.

Carleton A, Petreanu LT, Lansford R, Alvarez-Buylla A, Lledo PM (2003) Becoming a new neuron in the adult olfactory bulb. Nat Neurosci 6:507-518.

Dehmelt L, Smart FM, Ozer RS, Halpain S (2003) The role of microtubuleassociated protein $2 \mathrm{c}$ in the reorganization of microtubules and lamellipodia during neurite initiation. J Neurosci 23:9479-9490.

Dickson BJ (2002) Molecular mechanisms of axon guidance. Science 298:1959-1964.

Diefenbach TJ, Latham VM, Yimlamai D, Liu CA, Herman IM, Jay DG (2002) Myosin 1c and myosin IIB serve opposing roles in lamellipodial dynamics of the neuronal growth cone. J Cell Biol 158:1207-1217.

Gascon E, Vutskits L, Zhang H, Barral-Moran MJ, Kiss PJ, Mas C, Kiss JZ (2005) Sequential activation of p75 and TrkB is involved in dendritic development of subventricular zone-derived neuronal progenitors in vitro. Eur J Neurosci 21:69-80.

Ge S, Goh EL, Sailor KA, Kitabatake Y, Ming GL, Song H (2006) GABA regulates synaptic integration of newly generated neurons in the adult brain. Nature 439:589-593.

Gehler S, Gallo G, Veien E, Letourneau PC (2004) p75 neurotrophin receptor signaling regulates growth cone filopodial dynamics through modulating RhoA activity. J Neurosci 24:4363-4372.

Hamann M, Rossi DJ, Attwell D (2002) Tonic and spillover inhibition of granule cells control information flow through cerebellar cortex. Neuron 33:625-633.
Henley J, Poo MM (2004) Guiding neuronal growth cones using $\mathrm{Ca}^{2+}$ signals. Trends Cell Biol 14:320-330.

Joshi HC, Cleveland DW (1989) Differential utilization of beta-tubulin isotypes in differentiating neurites. J Cell Biol 109:663-673.

Kater SB, Mattson MP, Cohan C, Connor J (1988) Calcium regulation of the neuronal growth cone. Trends Neurosci 11:315-321.

Klages N, Zufferey R, Trono D (2000) A stable system for the high-titer production of multiply attenuated lentiviral vectors. Mol Ther 2:170-176.

Liu X, Wang Q, Haydar TF, Bordey A (2005) Nonsynaptic GABA signaling in postnatal subventricular zone controls proliferation of GFAPexpressing progenitors. Nat Neurosci 8:1179-1187.

Lledo PM, Saghatelyan A (2005) Integrating new neurons into the adult olfactory bulb: joining the network, life-death decisions, and the effects of sensory experience. Trends Neurosci 28:248-254.

Lois C, Garcia-Verdugo JM, Alvarez-Buylla A (1996) Chain migration of neuronal precursors. Science 271:978-981.

Mattson MP, Guthrie PB, Kater SB (1988) Components of neurite outgrowth that determine neuronal cytoarchitecture: influence of calcium and the growth substrate. J Neurosci Res 20:331-345.

Nusser Z, Mody I (2002) Selective modulation of tonic and phasic inhibitions in dentate gyrus granule cells. J Neurophysiol 87:2624-2628.

Price LS, Langeslag M, ten Klooster JP, Hordijk PL, Jalink K, Collard JG (2003) Calcium signaling regulates translocation and activation of Rac. J Biol Chem 278:39413-39421.

Represa A, Ben-Ari Y (2005) Trophic actions of GABA on neuronal development. Trends Neurosci 28:278-283.

Rivera C, Voipio J, Payne JA, Ruusuvuori E, Lahtinen H, Lamsa K, Pirvola U, Saarma M, Kaila K (1999) The $\mathrm{K}^{+} / \mathrm{Cl}^{-}$co-transporter KCC2 renders GABA hyperpolarizing during neuronal maturation. Nature 397:251-255.

Saghatelyan A, Roux P, Migliore M, Rochefort C, Desmaisons D, Charneau P, Shepherd GM, Lledo PM (2005) Activity-dependent adjustments of the inhibitory network in the olfactory bulb following early postnatal deprivation. Neuron 46:103-116.

Sonnewald U, Kortner TM, Qu H, Olstad E, Sunol C, Bak LK, Schousboe A, Waagepetersen HS (2006) Demonstration of extensive GABA synthesis in the small population of GAD positive neurons in cerebellar cultures by the use of pharmacological tools. Neurochem Int 48:572-578.

Stewart RR, Hoge GJ, Zigova T, Luskin MB (2002) Neural progenitor cells of the neonatal rat anterior subventricular zone express functional GABA(A) receptors. J Neurobiol 50:305-322.

Suter DM, Schaefer AW, Forscher P (2004) Microtubule dynamics are necessary for SRC family kinase-dependent growth cone steering. Curr Biol 14:1194-1199.

Thrower D, Jordan MA, Wilson L (1991) Quantitation of cellular tubulin in microtubules and tubulin pools by a competitive ELISA. J Immunol Methods 136:45-51.

Vaillant AR, Zanassi P, Walsh GS, Aumont A, Alonso A, Miller FD (2002) Signaling mechanisms underlying reversible, activity-dependent dendrite formation. Neuron 34:985-998.

Waagepetersen HS, Sonnewald U, Schousboe A (2003) Compartmentation of glutamine, glutamate, and GABA metabolism in neurons and astrocytes: functional implications. Neuroscientist 9:398-403.

Wayman GA, Kaech S, Grant WF, Davare M, Impey S, Tokumitsu H, Nozaki N, Banker G, Soderling TR (2004) Regulation of axonal extension and growth cone motility by calmodulin-dependent protein kinase I. J Neurosci 24:3786-3794.

Zhang H, Vutskits L, Pepper MS, Kiss JZ (2003) VEGF is a chemoattractant for FGF-2-stimulated neural progenitors. J Cell Biol 163:1375-1384. 